\title{
Thromboembolism and thromboprophylaxis in high risk surgery: facts and assumptions - a topic for emotions?
}

Major orthopaedic surgery is associated with serious coagulation related complications. Perioperative cardio-respiratory and vascular dysfunction have regularly been reported in connection with hip replacement surgery and account for a mortality up to $0.5 \%[1,2]$. Organ failure syndromes, myocardial insufficiency and infarction, brain stroke and clinical venous thromboembolism may occur from the time of the trauma and until many weeks after and account for additionally $3-4 \%$ [1,3-7].

\section{Inherited thrombophilic disorders}

Some patients seem predisposed to arterial and/or venous thromboembolic events. This may be due to abnormalities in the blood proteins regulating pro- and anticoagulant activities and several hereditary and acquired deficiencies have been described.

Since the frequency of thromboembolism increases with age and patients undergoing major joint surgery are predominantly in the older age groups, thrombophilic disorders could theoretically set these patients at a particularly high risk of postoperative thromboembolic complications. The prevalence of some of these thrombophilic defects could therefore be expected to increase. However, in patients over 85 years of age, the same prevalence of the Leiden $\mathrm{V}$ mutation was found as in young people and without any association with mortality $[8,9]$. In another study in patients over 65 years, Factor $\mathrm{V}$ Leiden was not found to be a risk factor for arterial thrombosis [10]. Another possibility is that the plasma levels of the

Accepted November 1999

Correspondence: O. E. Dahl, Ullevaal University Hospital, Department of Orthopaedics, Research Forum, Storgt 40, 0182 Oslo, Norway. coagulation inhibitors could increase with age. Sakkinen and co-workers [11], however, failed to find any association between age and the plasma levels of antithrombin, protein $\mathrm{C}$, protein $\mathrm{S}$ and tissue factor pathway inhibitor. Neither the coexistence of factor $\mathrm{V}$ Leiden genotype nor methylentetra-hydrofolate reductase (MTHFR) which is associated with thrombophilia, have been shown to increase the risk of thrombosis following high risk orthopaedic surgery whether assuming a recessive or a dominant allele model [1214]. One recent study showed that women heterozygous for factor $\mathrm{V}$ had an increased risk for late venous thrombosis after hip replacement surgery [15]. This result could not be confirmed in a similarly designed study [16]. Recently, an association between the genotype for angiotensin I-converting enzyme (involved in regulation of vascular tone) and the risk of postoperative thrombosis has been reported to increase the risk of DVT in patients undergoing joint arthroplasty [14]. It would appear, from the few and conflicting studies currently available, that underlying inherited diseases do not play an important role in the post-traumatic procoagulant process.

\section{Hypercoagulability}

For many years, we have focused on postoperative venous thromboembolism as an important cause of death. Recent research has shown that post-traumatic hypercoagulability affects both the venous and arterial circulation following major orthopaedic surgery. Trauma to the large bones causes extravasation of bone marrow cells [17]. These cells have a high content of tissue factor (TF) [18] and high blood concentrations have been measured by Giercksky and his coworkers [19]. This triggers activation of coagulation locally in 
veins draining the operative area [20]. Blood-borne procoagulant debris from the traumatized area is brought to the lungs where it triggers an additional substantial activation of coagulation and thrombin generation as the blood passes through the lungs. Significantly higher activation of coagulation has been found in arterial blood leaving the lungs as opposed to mixed venous blood entering the lungs during hip replacement surgery [21-23]. Thus, the lung capillaries seem to play a key role in the thrombin-generating process during major bone surgery.

Impaction of bone cement, which is frequently used to fix implanted prostheses, adds both a mechanical and a chemical component. This contributes to the coagulation process and to the formation of deep venous thrombosis $[20,24,25]$. In addition there is haemodynamic instability and a higher perioperative mortality when compared to non-cement prosthesis implantation [26].

Following the operation, reactivation of the coagulation process occurs when prophylaxis is stopped. This phenomenon has also been observed following cardiac disease and has resulted in an increase in angina pectoris and myocardial infarction [27-29]. Hypercoagulability seems to last for 6 weeks or more following hip arthroplasty particularly if prophylaxis is discontinued. This parallels reduced venous blood flow and an increased formation of late deep vein thrombosis [30,31].

\section{Thromboprophylaxis}

Many believe that mobilization is the best way to avoid venous thromboembolic complications, as stated in the Consumers Guide to Total Joint Replacement from the American Association of Hip and Knee Surgeons 1999. Although venous blood flow may be increased by more than $20 \%$ above the resting level [32], mobilization alone is often not enough to overcome the considerable pro-coagulant activity that has been found following major orthopaedic surgery (vide supra).

Patients may still be at risk from thromboembolic complications for many weeks after surgery [3-5,33]. Rapid and systematic mobilization did not seem to significantly influence thrombus formation in these patients. In a 4-week period after discharge, DVT progression was found to be approximately twice as frequent as DVT regression in spite of daily training under direct supervision by physiotherapists. About $20-25 \%$ of patients developed a DVT during the 3- to 4-week postdischarge period. Prolonged thromboprophylaxis with low molecular weight heparin (LMWH) (enoxaparin, dalteparin) reduced the frequency of thromboembolism to about half and is therefore highly recommended [7,34-37]. Whether other groups of patients should receive prophylaxis beyond discharge is at present unknown. It is tempting to speculate that patients having undergone surgery or major trauma to tissues with high pro-coagulant activity, for example the brain, should also receive longterm prophylaxis. The healing process can be prolonged in these patients and a high frequency of thrombembolic events has also been found [38].

\section{Neuraxial complications}

Attention has recently been paid to neurological deficits after surgery which have been assumed to be caused by an intravertebral haematoma induced by the combination of spinal nerve block and chemical thromboprophylaxis. Such complications have mainly been reported in North America and have mostly been associated with the use of LMWH. A $50 \%$ higher dose than that used in Europe has traditionally been administered postoperatively. The risk of inducing a spinal haematoma has been calculated to be in the order of 1 in 250000 after spinal puncture and 1 in 150000 after the use of an epidural catheter [39]. The Food and Drug Administration in the USA issued a 'black box warning' (1997) of this risk which all manufacturers of LMWH had to include in their drug information. The American Society of Regional Anesthesia also recommended in 1998 that concomitant use of NSAIDS should be avoided prior to surgery if spinal or epidural analgesia was planned. Many local recommendations based on these guidelines have appeared. At some hospitals these guidelines have almost been practised as rules with potential legal implications.

In placebo-controlled studies, the preoperative injection of LMWH carried no clinically significant increased risk of bleeding [40-43]. In an abstracted North American study, comparing LMWH administered at the time of the surgical procedure with postoperative $\mathrm{LMWH}$, a nonsignificant, slightly increased bleeding tendency was found in the first group [37]. In 
a prospective controlled trial, perioperative administration of NSAIDs together with LMWH were found not to increase bleeding when compared to LMWH alone [44].

\section{The validity of statistics}

Official death rates for patients dying from pulmonary embolism have been questioned. In general, the autopsy rate is low (about 15\%) in Western countries. In addition, routine autopsies may overlook a number of cases of pulmonary embolism both as a contributing cause of death and as the main cause of death [45] This contributes further to the under-reporting of the number of patients with pulmonary embolism.

Retrospective descriptive studies of a population of interest may give a rough overview of the magnitude of the problem and an hypothesis may be provided. To test the hypothesis, prospective more rigorously designed studies have to be performed. The most powerful study design we have is the prospective double-blind randomized study. This study design is commonly used to compare the efficacy and safety of two anticoagulants. To reach an objective figure for the number of confirmed deep vein thromboses, venography is necessary since the clinical diagnosis of thromboembolism is unreliable after surgery. However, interpretation of data from such studies may be open to question. Selection of study patients and exclusion of patients from the final statistical analysis will automatically lower the estimates of actual events. In addition, treatment of patients who have reached the surrogate endpoint, i.e. DVT, and the fact that pulmonary embolism often is a secondary endpoint, will further contribute to an underestimate of the actual number of thromboembolic events in the basic population. Finally, focusing only on venous complications without including arterial thromboembolic events will also help to obscure the clinical reality of such complications. Meta-analysis based on 'super-studies' is likely to underestimate the real number of patients with postoperative coagulation-related complications. Figures concerning the number of venous thromboembolic events in a specific population is often wrongly extracted from such studies.

\section{New avenues}

It has repeatedly been shown that pulmonary embolism is mostly a postmortem diagnosis missed by the clinicians. This strongly indicates that subclinical DVT is the main source of these fatalities [46-49]. Since post-traumatic hypercoagulability is a systemic phenomenon, future studies should include both venous and arterial vascular complications. Such an approach may show a more realistic picture of posttraumatic vascular morbidity and mortality than has been apparent to date due to studies focusing only on deep vein thrombosis as primary outcome measure. However, as previously noted, surrogate endpoints are of great value and should also be included as an endpoint measurement. To optimize the duration of prophylaxis on an individual basis, studies on haemostatic markers may also be of value [50].

It is possible that we have reached an efficacy/safety optimum at least in surgery with moderate prothrombotic risk using recommended doses of available LMWHs [51]. On the threshold of a new millennium, potent new anticoagulants are imminent. The question of whether preoperative or postoperative administration is preferable with these new drugs will hopefully be determined on the basis of well-designed studies and not on the emotional feelings of physicians.

\section{O. E. Dahl Oslo, Norway}

\section{References}

1 Dahl OE. Cardiorespiratory and vascular dysfunction related to major reconstructive orthopaedic surgery. Acta Orthop Scand 1997; 68: 607-614.

2 Hamborg Andersen K, Mahler Nielsen J. Knoglecementens herdningsvarme kan udløse hjertestop. J Danish Med Ass 1998; 160: 4905-4906.

3 Warwick D, Williams MH, Bannister GC. Death and thromboembolic disease after total hip replacement. $J$ Bone Joint Surg 1995; 77-B: 610.

4 Seagroatt V, Tan HS, Goldacre M, Bulstrode C, Nugent I, Gill L. Elective total hip replacement: incidence, emergency readmission rate, and postoperative mortality. BMJ 1996; 7: 1431-1435.

5 Fender D, Harper WH, Thompson JR, Gregg PJ. Mortality and fatal pulmonary embolism after primary total hip replacement. Results from a regional hip register. $J$ Bone Joint Surg 1997; 79-B: 896-899.

6 Dahl OE, Gudmundsen TE, Haukeland L. Late occurring clinical deep vein thrombosis in joint operated patients. Acta Orthop Scand 2000; 71: in press.

7 Dahl OE, Andreassen G, Aspelin T, et al. Prolonged 
thromboprophylaxis following hip replacement surgery. Thromb Haemost 1997; 1: 26-31.

8 Kristensen SR, Andersen-Randberg K, Bathum L, Jeune $B$. Factor $V$ Leiden and venous thrombosis in Danish centenarians. Thromb Haemost 1998; 80: 860-861.

9 Heijmans TB, Westendorp RGJ, Knook DL, Kluft C, Slagboom PE. The risk of mortality and the factor $\mathrm{V}$ Leiden mutation in a population based cohort. Thromb Haemost 1998; 80: 607-609.

10 Cushman M, Rosendaal FR, Psaty BM, et al. Factor V Leiden is not a risk factor for arterial vascular disease in the elderly: results from the cardiovascular health study. Thromb Haemost 1998; 79: 912-915.

11 Sakkinen PA, Cushman M, Psaty BM, et al. Correlates of antithrombin, protein $C$, Protein $S$ and TFPI in a healthy elderly cohort. Thromb Haemost 1998; 80: 134-139.

12 Zehnder JL, Woolson ST, Maloney J. Factor V Leiden and the risk of post-operative deep vein thrombosis after total joint replacement. Thromb Haemost 1997; (Suppl.): 309.

13 Ryan DH, Crowther MA, Ginsberg JS, Francis CW. Relation of factor $\mathrm{V}$ Leiden genotype to risk for acute deep venous thrombosis after joint replacement surgery. Ann Int Med 1998; 128: 270-276.

14 Philipp CS, Dilley A, Saidi $\mathrm{P}$, et al. Deletion polymorphism in the angiotensin-converting enzyme gene as a thrombophilic risk factor after hip arthroplasty. Thromb Haemost 1998; 80: 869-873.

15 Svensson PJ, Benoni G, Fredin H, et al. Female gender and resistance to activated protein C (FV. Q506) as potential risk for thrombosis after elective hip arthroplasty. Thromb Haemost 1997; 78: 993-996.

16 Sandset PM, Dahl OE, Mowinckel MC, Aspelin T. Activated protein $C$ (APC) resistance and risk of venous thromboembolism after elective hip replacement surgery. Thromb Haemost 1999; (Suppl.): 589.

17 Modig J, Bush C, Olerud S, Saldeen T, Waernbaum G. Arterial hypotension and hypoxemia during total hip replacement; The importance of thromboplastic products, fat embolism and acrylic monomers. Acta Anaesthesiol Scand 1975; 19: 28-43.

18 Giercksky KE. The procoagulant activity of adipose tissue. Scand J Haematol 1977; 19: 385-395.

19 Giercksky KE, Bjørklid E, Prydz H, Renck H. Circulating tissue thromboplastin during hip surgery. Eur Surg Res 1979; 11: 296-300.

20 Dahl OE, Aspelin T, Lyberg T. The role of bone traumatization and methylmethacrylate monomer cytotoxicity in the initiation on proximal deep vein thrombosis during cemented hip replacement in pigs. Blood Coag Fibrinol 1995; 6: 709-717.

21 Dahl OE, Molnar I, Rø J, et al. Studies on coagulation, fibrinolysis, kallikrein-kinin and complement activation in systemic and pulmonary circulatioin during hip arthroplasty with acrylic cement. Thromb Res 1988; 50: 875-884.
22 Dahl $\mathrm{OE}$, Johnsen $\mathrm{H}$, Kierulf $\mathrm{P}$, et al. Intrapulmnoary thrombin generation and its relation to monomethylmethacrylate plasma levels during hip arthroplasty. Acta Anaesth Scand 1992; 36: 331-335.

23 Dahl OE, Pedersen T, Kierulf $P$, et al. Sequential intrapulmonary and systemic activation of coagulation and fibrinolysis during and after hip replacement. Thromb Res 1993; 70: 451-458.

24 Sharrock NE, Go G, Harpel PC, Ranawat CS, Sculco TP, Salvati EA. The John Charnley Award. Thrombogenesis during total hip arthroplasty. Clin Orthop 1995; 319: 1627.

25 Clarke MT, Green JS, Harper WM, Gregg PJ. Cement as risk factor for deep-vein thrombosis. Comparison of cemented TKR, uncemented TKR and cemented THR. J Bone Joint Surg 1998; 80-B: 611-613.

26 Lennox IA, McLaughlan L. Comparing the mortality and morbidity of cemented and uncemented hemiarthroplasties. Injury 1993; 24: 185-186.

27 Gallino A, Haeberli A, Hess T, Mobelli G, Straub PW. Fibrin formation and platelet aggregation in patients with acute myocardial infarction: effects of intravenous and subcutaneous low dose heparin. Am Heart J 1986; 112: 285290.

28 Gold HK, Torres FW, Garabedian HD, et al. Evidence for a rebound coagulation phenomenon after cessation of a 4hour infusion of a specific thrombin inhibitor in patients with unstable angina. J Am Coll Cardiol 1993; 21: 10391047.

29 Granger CB, Miller JM, Bowill EG, et al. Rebound increase in thrombin generation and activity after cessation of intravenous heparin in patients with acute coronary syndromes. Circulation 1995; 1: 1929-1935.

30 McNally MA, Mollan RAB. Total hip replacement, lower limb blood flow and venous thrombogenesis. J Bone Joint Surg 1993; 75: 640-644.

31 Dahl OE, Aspelin T, Arnesen $\mathrm{H}$, et al. Increased activation of coagulation and formation of late deep venous thrombosis following discontinuation of thromboprophylaxis after hip replacement surgery. Thromb Res 1995; 80: 299306.

32 MacNally MA, Cooke EA, Mollan RAB. The effect of active flow movement of the foot on venous blood flow after total hip replacement. J Bone Joint Surg 1997; 79-A: 11981201.

33 McGrath D, Dennyson WG, Rolland M. Death rate from pulmonary embolism following joint replacement surgery. J R Coll Surg Edinb 1996; 41: 265-266.

34 Planes A, Vochelle N, Darmon JY, Fagola M, Bellaud M, Huet Y. Risk of deep-venous thrombosis after hospital discharge in patients having undergone total hip replacement: double-blind randomised comparison enoxaparin versus placebo. Lancet 1996; 348: 224-228.

35 Bergqvist D, Benoni G, Bjorgell O, et al. Low-molecularweight heparin (enoxaparin) as prophylaxis against 
venous thromboembolism after total hip replacement. $N$ Engl J Med 1996; 335: 696-700.

36 Lassen MR, Borris LC, Anderson BS, et al. Efficacy and safety of prolonged thromboprophylaxis with a low molecular weight heparin (dalteparin) after total hip arthroplasty - The Danish prolonged prophylaxis study. Thromb Res 1998; 89: 281-287.

37 Hull RD, Pineo GF. A double blind, randomized comparison of extended out-of-hospital prophylaxis using dalteparin versus placebo in patients undergoing elective hip replacement. Thromb Haemost 1999; (Suppl.): 6.

38 Agnelli G, Piovella F, Buoncristiani P, et al. Enoxaparin plus compression stockings compared with compression stockings alone in the prevention of venous thromboembolism after elective neurosurgery. N Engl J Med 1998; 339: 80-85.

39 Tryba M. Epidural regional anaesthesia and low molecular weight heparin. Pro Anasthesiol Intensivmed Notfallmed Schmerzther 1993; 28: 179-181.

40 Turpie AGG, Levine MN, Hirsch J, et al. A randomized controlled trial of low-molecular-weight heparin (enoxaparin) to prevent deep-vein thrombosis in patients undergoing elective hip surgery. N Engl J Med 1986; 315: 925-929.

41 Tørholm C, Broeng L, Jørgensen PS, et al. Thromboprophylaxis by low-molecular-weight heparin in elective hip surgery. A placebo controlled trial. J Bone Joint Surg 1991; 73-B: 434-438.

42 Lassen MR, Borris LC, Christiansen HM, et al. Prevention of thromboembolism in 190 hip arthroplasties. Comparison LMWH Heparin Placebo Acta Orthop Scand 1991; 62: 33-38.
43 Leclerc JR, Geerts WH, Desjardins L, et al. Prevention of deep vein thrombosis after major knee surgery - a randomized double-blind trial comparing a low molecular weight heparin fragment (enoxaparin) to placebo. Thromb Haemost 1992; 67: 417-423.

44 Weale AE, Warwick DJ, Durant N, Prothero D. Is there a clinical interaction between low molecular weight heparin and non-steroidal analgesics after total hip replacement? Ann R Coll Surg Engl 1995; 77: 35-37.

45 Morrell MT, Dunnhill MS. The post-mortem incidence of pulmonary embolism in a hospital population. Bit J Surg 1968; 55: 347-352.

46 Havig O. Deep vein thrombosis and pulmonary embolism. An autopsy study with multiple regression analysis of possible risk factors. Acta Chir Scand 1977; (Suppl.).

47 Sandler DA, Martin JF. Autopsy proven embolism in hospital patients: are we detecting enough deep vein thrombosis? J Roy Soc Med 1989; 82: 203-205.

48 Goldhaber SZ, Hennekens CH, Evans DA, Newton EC, Godleski JJ. Factor associated with correct antemortem diagnosis of major pulmonary embolism. Am J Med 1982; 73: 822-826.

49 Karwinski B. The significance of autopsy in modern medicine. A study from western Norway. PhD Thesis, University of Bergen, Norway, 1995.

50 Seljeflot I, Arnesen H, Dahl OE, Aspelin T, Kierulf P, Lyberg $\mathrm{T}$. Increased prothrombotic activity 35 days after hip replacement surgery related to the occurrence of DVT. Thromb Haemost 1999; (Suppl.): 255-256.

51 Bergqvist D, Burmark US, Flordal PA, et al. Low molecular weight heparin started before surgery as prophylaxis against deep vein thrombosis: 2500 versus 5000 Xai units in 2070 patients. Br J Surg 1995; 82: 496-501. 